\title{
Understanding the Role of Personality Traits on Beliefs in Online Learning
}

\author{
Raafat George Saadé, Dennis Kira \& Fassil Nebebe \\ Department of Decision Sciences and Management Information \\ Systems, Concordia University, John Molson School of \\ Business, Montréal, Québec, Canada \\ rsaade@jmsb.concordia.ca; dkira@jimsb.concordia.ca; \\ fnebebe@jmsb.concordia.ca
}

\begin{abstract}
In an educational setting, the use of online learning tools impacts student's performance. Attitudes and perceived usefulness play an important role in predicting students' decision to use these learning tools. A students' attitude towards the use of online learning tools is impacted by his/her perception of usefulness of the tools. In this study, we investigate the mediating effects of personality traits (computer playfulness and perceived personal innovativeness) and cognitive traits (enjoyment) on the perceived usefulness - attitudes relationship. The study includes ninety five participants. A survey was conducted after using the learning tool for one semester. Assessment of the psychometric properties of the scales proved acceptable and confirmatory factor analysis supported the proposed hypotheses. Analysis of results demonstrate that cognitive traits while using the learning tool significantly mediate the impact of perceived usefulness on attitudes, while personality traits do not. Implications to designers and managers point towards game-based learning systems. Limitations and suggestions for future research are provided.
\end{abstract}

Keywords: Computer-assisted learning; playfulness; personal innovativeness; enjoyment; attitudes; TAM; perceived usefulness; structural equation modeling.

\section{Introduction}

Recently, great interest in the use of online learning tools has been generated. The value of online learning has become widely recognized and accepted as an approach to enhance the classroom environment. Expected productivity gains and benefits to students and academic institutions delivered by learning technologies cannot be realized unless they are effectively used (Hackbarth, et. al., 2003). Acceptance has been identified as a critical issue in the successful usage of the learning technologies. However, acceptance of learning tools usage is not likely unless students perceive it to be useful and are motivated to use it.

Material published as part of this publication, either on-line or in print, is copyrighted by the Informing Science Institute. Permission to make digital or paper copy of part or all of these works for personal or classroom use is granted without fee provided that the copies are not made or distributed for profit or commercial advantage AND that copies 1) bear this notice in full and 2) give the full citation on the first page. It is permissible to abstract these works so long as credit is given. To copy in all other cases or to republish or to post on a server or to redistribute to lists requires specific permission and payment of a fee. Contact Publisher@InformingScience.org to request redistribution permission.
The technology acceptance model (TAM) which is the model most widely applied to technology adoption, has been recently used to study the acceptance of computer-assisted applications (Saadé \& Bahli, 2005; Saadé et al., 2007). The TAM theorizes that perceived usefulness influences attitudes towards learning tools usage and is an 
important determinant to student's intentions to use the learning tool.

In this study, two student's traits, perceived personal innovativeness and playfulness on the web, and enjoyment (cognitive trait) were used to study their mediating effects on the impact of perceived usefulness on attitudes in the learning tools usage context. Our study involved 95 students that used a learning tool (developed in-house) as part of a course's requirements. It examined the effect of perceived usefulness on attitudes as affected by perceived personal innovativeness, playfulness on the web and enjoyment. Prior research in information systems has investigated the five constructs mentioned herein to understand individual reactions to computer systems (Agarwal and Karahanna, 2000; Abbad et al., 2009). However, few studies have used web-based learning tools as the target technology and have directly compared and contrasted the constructs to understand the impact of experience on user perceptions.

In recent years, however, researchers have studied as to what extent the impact of external variables have on relationship amongst TAM model constructs and the acceptance of web-based tools by the students and teachers. Many modified version to original TAM have appeared where extended version of the TAM to investigate factors that influence a student's decision to use an elearning management system (Raman, 2011; Davis and Wong, 2007; Abbad et al.; Šumak, et al., 2011).

Building upon previous research work on user acceptance of information technology, this study seeks to apply the TAM constructs to learning tools and advance our understanding of the effects of perceived usefulness on attitudes via both specific personality (perceived personal innovativeness and computer playfulness) and cognitive (enjoyment) traits.

\section{Theoretical Background and Research Hypotheses}

\section{Perceived Usefulness and Attitudes}

Perceived usefulness and attitude are based on the TAM developed by Davis $(1986,1989)$. In general, TAM identifies the relationships between perceived ease of use, perceived usefulness, attitudes, and behavioral intentions towards a target system. In the context of the present study, perceived usefulness (PU) is defined as the degree to which a student believes that using the learning tool could enhance his or her course performance: it is the extent to which a student believes that using the learning tool enhances his/her performance. Enhanced course performance implies that the student can obtain a better grade by using the learning tool. Students' perception of enhanced performance affects attitudes. In other words, students that perceive the system to be useful, develop better attitudes towards the learning tool as reported by previous studies (Sun and Zhang, 2006, 2008).

Moreover, empirical evidence suggests that direct experience leads to the formation of an attitude (Triandis, 1980). A number of IS studies (Chang and Cheung, 2001; Liao and Cheung, 2001) have examined the effect of perceived usefulness on usage and have found these to be important determinants of self-reported system use. Attitude toward using learning tools was predicted primarily by perceived usefulness (Chau, 1996). Students that believe in a use-performance relationship with the learning tool also believe that by using it, their performance in the course would improve. Consequently, we hypothesize:

H1: Perceived usefulness will have a strong positive effect on students' attitude towards the learning tool. 


\section{Enjoyment}

Although TAM's emphasis is on the behavior of a student towards using information technology, little is known on the student's experience while using the technology (Abbad et al.; Terzis et al., 2012). The holistic approach includes capturing constructs such as the individual's level of enjoyment while interacting with the learning tool. Such constructs were found to be significant predictors to outcomes related to technology use and acceptance. Previous work suggested that there are positive outcomes from a holistic type of engagement (Sun and Zhang). These may include more positive attitudes towards learning tools.

The enjoyment dimension stems from the concept of cognitive absorption (CA). The CA variables represent one form or another of intrinsic motivation, where "a behavior is performed for itself, in order to experience pleasure and satisfaction inherent in the activity" (Agarwal and Karahanna). While in a state of CA, the student is experiencing gratification and pleasure from the task of interacting with the learning tool. Therefore, through the heightened enjoyment dimension, a state of cognitive absorption is expected to influence perceived usefulness. In essence, the student rationalizes "I am spending a lot of time on this and enjoying it, therefore it must be truly useful”. Therefore, we hypothesize:

H2: Enjoyment mediates the effect of perceived usefulness on attitudes towards computer-assisted learning tools.

\section{Perceived Personal Innovativeness}

Perceived personal innovativeness is an individual trait reflecting the willingness to try out any new technology (Nov and Chen, 2008; Wang et al., 2012). It would be expected that students that are more willing to experiment and learn new computer applications may have stronger feelings about the usefulness of these computer applications. It is probably their sense of usefulness of these computer applications that motivates them to try them out. Or possibly, it could be the students' feeling to discover new applications useful for their studies and careers. Based on the definition of PPI, we hypothesize:

H3: Perceived personal innovativeness mediates the effect of perceived usefulness on attitudes towards computerassisted learning tools.

\section{Playfulness on the Web}

Computer playfulness refers to a students' tendency to interact spontaneously with a computer (Atkinson and Kydd, 1997; Lee et al., 2005; Terzis et al.; Šumak et al.). This construct can be viewed as a cognitive state experience by the student while interacting with the learning tool, or a characteristic of the student. While a student may be considered playful in the way he/she use the computer, his/her specific level of playfulness towards the learning tool may differ. This is consistent with previous finding (Yager et al., 1997). When students first use the learning tool, they may feel uncomfortable and stressed with the environment, hence their degree of playfulness is low. However, as they become familiar with the learning tool, they become more spontaneous in interacting with it. Vankatesh (1999) demonstrated that game-based training induced a higher level of playfulness and enhanced users' intrinsic motivation, which is a form of perceived usefulness. Therefore, we hypothesize: 
H4: Playfulness on the web mediates the effect of perceived usefulness on attitudes towards computer-assisted learning tools.

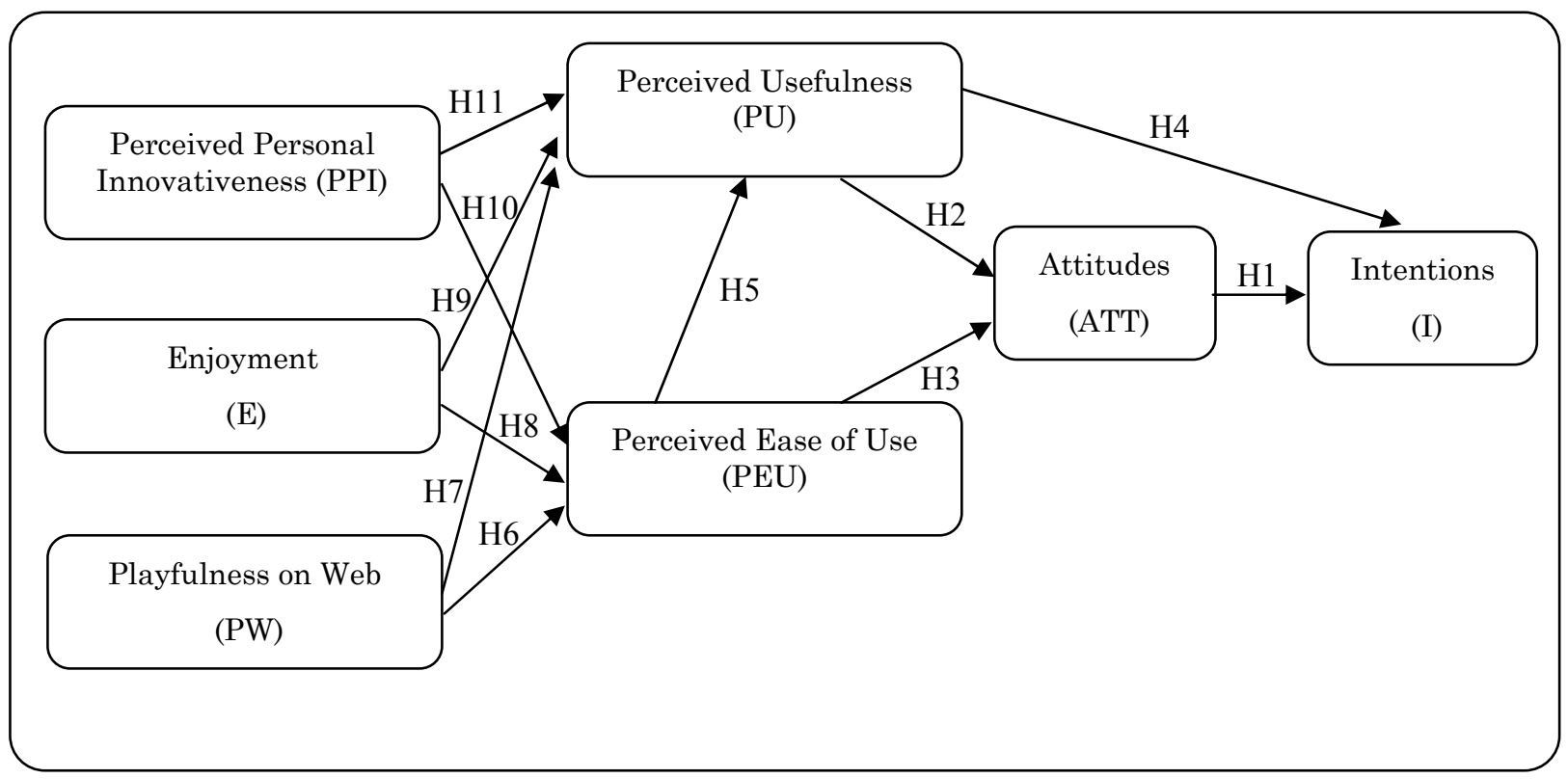

Fig. 1. The Research model.

H1: Perceived usefulness has a significant effect on attitudes towards computer-assisted learning

\begin{tabular}{|c|c|}
\hline $\begin{array}{l}\text { Perceived Usefulness } \\
\text { (PU) }\end{array}$ & Attitutes/Intention \\
\hline
\end{tabular}

H2: Enjoyment significantly mediates the effect of perceived usefulness on attitudes towards computer-assisted learning tools.

H3: Perceived personal innovativeness mediates the effect of perceived usefulness on attitudes towards computer-assisted learning tools.

H4: Playfulness on the web mediates the effect of perceived usefulness on attitudes towards comnuter-assisted learning tonls

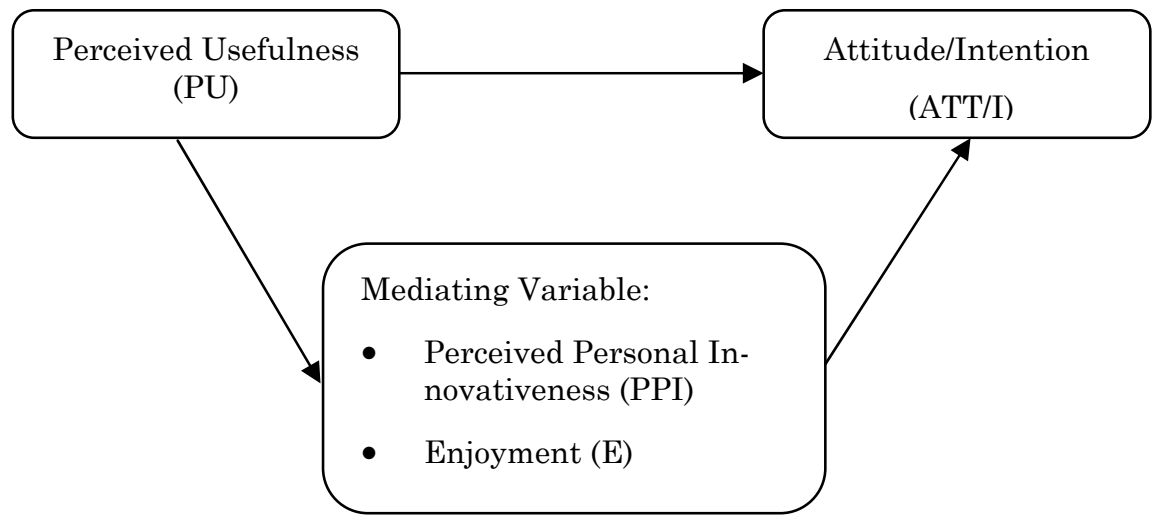

Fig. 2. The Research model. 


\section{The Study}

The study was conducted in an undergraduate course setting spanning one semester, using a learning tool (developed in-house) as the target system. Throughout one semester, students in an introductory undergraduate management information systems course at a major university in Montreal, Canada, used the learning tool as part of the course requirements. The objective of the learning tool was to help them understand course topics by practicing multiple choice and true or false questions. The learning tool is web-based and students were able to access it anywhere, anytime. The system monitored the students' activities by storing the time spent on the system, the chapters practiced, and scores.

At the end of the semester, a survey instrument was administered. Ninety five students participated in this study. Respondents were $52 \%$ female and $48 \%$ male with a mean age of 23 years. The respondents had an average of 2 years of experience, use the internet close to one hour a day and claim to have strong knowledge of basic software utilization.

Items (presented in the Appendix) used to measure the constructs were adopted from prior research work namely (Davis et al. 1989; Venkatesh and Davis, 2000). The items were validated in a pilot study and some wording was changed to account for the context of using learning tools. All items were measured using a five-point Likert-type scale with anchors from "Strongly disagree" to "Strongly agree".

\section{Analysis of Findings}

First, the 95 usable questionnaires were examined for missing data: they showed a few missing values and a mean substitution was used to generate replacement values for all the missing data. The Cronbach's alpha coefficient for internal consistency reliability was first assessed. As summarized in Table 1, the reliability of most of all constructs was acceptable (Nunnally, 1978).

Table 1. Reliability assessment.

\begin{tabular}{lccc}
\hline & Cronbach alpha, $\alpha$ & Mean & SD \\
\hline Perceived Usefulness (PU) & 0.821 & 3.76 & 0.67 \\
Attitude (ATT) & 0.823 & 3.16 & 0.48 \\
Enjoyment (E) & 0.864 & 3.36 & 0.82 \\
Intentions (I) & 0.620 & 2.90 & 0.90 \\
Playfulness on the Web (PW) & 0.790 & 3.68 & 0.70 \\
Perceived Personal Innovativeness (PPI) & 0.890 & 3.56 & 0.88 \\
\hline
\end{tabular}

Second, reliabilities of individual items were assessed by examining the loadings of the items on their respective constructs presented in Table 2 . These loadings should be higher than 0.5 , following the criterion used by Rivard and Huff (1988) to indicate that significant variance was shared between each item and the construct. It is expected that the loadings of all items within a construct should be high on that construct, indicating high convergent validity, and low on the others. The factors, underlying variables that reflect combinations of observable variables, were extracted using the principal components method (varimax rotation) which is an optimum approach to condensation prior to rotation (Deci and Ryan, 1985). Table 1 clearly shows that the five-factor solution is appropriate and the items display desirable convergent and discriminant validity. 
Table 2. Factor analysis.

\begin{tabular}{ccccccc}
\hline & Factor 1 & Factor 2 & Factor 3 & Factor 4 & Factor 5 & Factor 6 \\
\hline PU1 & 0.170 & $\mathbf{0 . 5 5 8}$ & 0.083 & -0.040 & -0.188 & 0.235 \\
PU2 & 0.020 & $\mathbf{0 . 8 8 0}$ & 0.276 & 0.061 & -0.109 & 0.174 \\
PU3 & 0.032 & $\mathbf{0 . 8 1 4}$ & 0.314 & 0.053 & -0.093 & 0.215 \\
ATT1 & 0.108 & 0.431 & 0.419 & 0.041 & $\mathbf{- 0 . 5 3 6}$ & 0.005 \\
ATT2 & 0.200 & 0.280 & 0.366 & 0.067 & $\mathbf{- 0 . 7 2 8}$ & 0.181 \\
E1 & 0.037 & 0.193 & $\mathbf{0 . 8 5 2}$ & -0.027 & -0.024 & 0.169 \\
E2 & 0.153 & 0.229 & $\mathbf{0 . 7 0 0}$ & 0.068 & -0.346 & 0.114 \\
E3 & 0.145 & 0.331 & $\mathbf{0 . 7 0 9}$ & 0.002 & -0.281 & 0.011 \\
I1 & 0.437 & 0.268 & 0.256 & 0.004 & 0.221 & $\mathbf{0 . 8 5 8}$ \\
I2 & 0.402 & 0.290 & 0.330 & 0.205 & 0.108 & $\mathbf{0 . 8 4 1}$ \\
PPI1 & 0.240 & 0.226 & 0.124 & $\mathbf{0 . 7 9 8}$ & 0.038 & 0.013 \\
PPI2 & 0.209 & -0.185 & -0.059 & $\mathbf{0 . 6 2 2}$ & -0.051 & 0.167 \\
PPI3 & 0.156 & 0.048 & -0.006 & $\mathbf{0 . 8 4 1}$ & -0.055 & 0.032 \\
PW1 & $\mathbf{0 . 6 9 5}$ & 0.093 & 0.079 & 0.044 & -0.131 & 0.020 \\
PW2 & $\mathbf{0 . 8 6 3}$ & 0.037 & 0.135 & 0.185 & -0.087 & 0.023 \\
PW3 & $\mathbf{0 . 8 6 5}$ & -0.003 & 0.187 & 0.267 & -0.052 & 0.155 \\
PW4 & $\mathbf{0 . 7 2 5}$ & 0.169 & -0.072 & 0.294 & -0.015 & 0.245 \\
\hline
\end{tabular}

The proposed mediation hypotheses were tested based on structural equation model estimates obtained from EQS runs. Mediation is considered to be established based on the following criteria: (1) A significant relationship exists between the independent variable and the dependent variable; (2) a significant relationship exists between the independent variable and the presumed mediator; and (3) in the presence of a significant relationship, the previous significant relationship between the independent variable and the dependent variable is no longer significant or the strength $\mathrm{f}$ the relationship is significantly decreased.

H1 hypothesized that PU has a significant effect on ATT. As shown in Table 3, the effect of PU on ATT was significant $(\beta=0.35, \mathrm{p} \leq 0.001)$, supporting H1. Hypothesis 2 (H2) stated that the effect of PU on ATT would be mediated by enjoyment. The relationship between PU and E was significant $(\beta=0.62, p \leq 0.001)$. When ATT was regressed on both E and PU, a significant relationship was found between E and ATT $(\beta=0.02, p \leq 0.001)$ and PU and ATT $(\beta=0.22, p \leq$ 0.01). Although the effect of PU on ATT was still significant, the strength of the relationship was reduced by $59 \%$ from $\beta=0.35$ to $\beta=0.22$ when $E$ was included as a mediator, thus partially supporting $\mathrm{H} 2$.

The links between PU and PPI and PU and PW in H3 and H4 were significant with a $\beta=0.17$ ( $\mathrm{p} \leq$ $0.05)$, and $\beta=0.24(p \leq 0.01)$ respectively. In both hypotheses, the link between PU and ATT was unchanged with $\beta=0.34(\mathrm{p} \leq 0.001)$ thereby indicating that mediation did not occur. 
Table 3. Results of hypothesis testing.

\begin{tabular}{ccccccc}
\hline Hypothesis & Result & $\begin{array}{c}\text { Dependent } \\
\text { variable }\end{array}$ & $\mathrm{R}^{2}(\%)$ & $\begin{array}{c}\text { Independent } \\
\text { variable }\end{array}$ & $\beta$ & $\mathrm{p}$ \\
\hline H1 & Supported & ATT/I & $23 / 20$ & PU & $0.35 / 0.45$ & $* * *$ \\
H2 & Supported & ATT/I & $32 / 36$ & PU & $0.22 / 0.12$ & $* *$ \\
& & ATT/I & & E & $0.20 / 0.41$ & $* * *$ \\
& & E & $25 / 40$ & PU & $0.62 / 0.64$ & $* * *$ \\
H3 & \multirow{2}{*}{ Not Supported } & ATT/I & $1 / 29$ & PU & $0.34 /-0.37$ & $* * *$ \\
& & ATT/I & & PPI & $0.02 /-0.32$ & ns \\
& & PPI & $2 / 5$ & PU & $0.17 / 0.22$ & $* * *$ \\
H4 & \multirow{4}{*}{ Not Supported } & ATT/I & $24 / 24$ & PU & $0.34 /-0.367$ & $* * *$ \\
& & ATT/I & & PW & $0.03 / 0.22$ & ns \\
& & PW & $6 / 11$ & PU & $0.24 /-0.34$ & $* *$
\end{tabular}

$* \mathrm{p} \leq 0.05 ;{ }^{* *} \mathrm{p} \leq 0.01 ; * * * \mathrm{p} \leq 0.001 ; \mathrm{ns}=$ not significant

Table 4. Simulations.

\begin{tabular}{|c|c|c|c|c|c|c|}
\hline $\begin{array}{l}\text { Influence Configuration } \\
\text { (IC) }\end{array}$ & E & PW & PPI & $\mathrm{v} \rightarrow \mathrm{PEU}$ & $\mathrm{v} \rightarrow \mathrm{PU}$ & PEU-PU \\
\hline IC \# 1 & 1 & 0 & 0 & 0.438 & 0.608 & 0.073 \\
\hline IC \# 2 & & & & $(19 \%)$ & \multicolumn{2}{|c|}{$(41 \%)$} \\
\hline IC \# 2 & 0 & 1 & 0 & -0.330 & -0.252 & 0.261 \\
\hline IC \# 3 & & & & $(11 \%)$ & \multicolumn{2}{|c|}{$(18 \%)$} \\
\hline IC \# 4 & 0 & 0 & 1 & -0.181 & -0.177 & 0.311 \\
\hline $\mathrm{IC} \# 5$ & & & & $(3 \%)$ & \multicolumn{2}{|c|}{$(15 \%)$} \\
\hline & & & & & & \\
\hline IC \# 6 & 1 & 1 & 0 & 0.377 & 0.578 & 0.035 \\
\hline IC \# 7 & & & & -0.217 & -0.162 & \\
\hline IC \# 8 & & & & $(24 \%)$ & \multicolumn{2}{|c|}{$(44 \%)$} \\
\hline IC \# 9 & 1 & 0 & 1 & 0.419 & 0593 & 0.060 \\
\hline IC \# 10 & & & & -0.099 & -0.109 & \\
\hline IC \# 11 & & & & $(20 \%)$ & \multicolumn{2}{|c|}{$(43 \%)$} \\
\hline IC \# 12 & 0 & 1 & 1 & -0.313 & -0.213 & 0.259 \\
\hline IC \# 13 & & & & -0.035 & -0.084 & \\
\hline IC \# 14 & & & & $(11 \%)$ & \multicolumn{2}{|c|}{$(18 \%)$} \\
\hline IC \# 15 & 1 & 1 & 1 & 0.376 & 0.576 & 0.034 \\
\hline IC \# 16 & & & & -0.213 & -0.139 & \\
\hline IC \# 17 & & & & -0.008 & -0.051 & \\
\hline IC \# 18 & & & & $(24 \%)$ & \multicolumn{2}{|c|}{$(44 \%)$} \\
\hline
\end{tabular}

$\mathrm{PU} \rightarrow \mathrm{ATT}=-0.606 ; \mathrm{PEU} \rightarrow \mathrm{ATT}=-0.211 ; \mathrm{ATT} \rightarrow \mathrm{I}=-0.383 ; \mathrm{PU} \rightarrow \mathrm{I}=0.185 ; \mathrm{PU}=12 \%$;

$\mathrm{ATT}=50 \% ; \mathrm{I}=28 \% ; \mathrm{V}=\mathrm{E} ; \mathrm{PW} ; \mathrm{PPI}$ 


\section{Discussion and Conclusions}

The primary objective of this study was to investigate the role of perceived personal innovativeness, enjoyment and playfulness they play in mediating the impact of perceived usefulness on attitudes, in the context of learning tool utilization. Of the three mediators, PPI, E and PW, only E was shown to mediate the impact of PU on ATT thereby supporting H1 and H2.

The analysis demonstrated the non-significant role of mediation played by PPI and PW contrary to what is implied by prior research and hypothesized in this study. The analysis results seem to suggest that computer related personality traits do not influence the perceived usefulness - attitude relationship in the use of online learning tools. Cognitive traits seem to be the dominant factors in the perception-attitude link for online learning tools usage. This alone has major significant impact on how educational information systems in general and learning tools in specific should be designed and implemented.

Finally, it is noteworthy that PU had a significant influence on PPI and PW. This implies that students who perceived the learning tool to be more useful also felt more playful and innovative in their interactions with the computer. This may suggest that students with more PU may feel more intrinsically motivated to use the learning tool. Hence, this increased feeling of innovativeness and playfulness may have an indirect effect on attitudes thereby implying the presence of other intermediary variables.

\section{Limitations}

Few limitations to this study exist and should be noted. First, the questionnaire approach is not free of subjectivity in the respondent and was taken at one point in time. User reactions change in time and may depend on the environment such as the classroom location and time of course. Second, caution must to be taken in generalizing the results due to the fact that participants in this study were from different cultural background with different cultural beliefs influencing their perceptions and attitudes.

Also, previous studies have shown that perceptions and attitudes differ between the mandatory or voluntary use of information technology (in this case, the learning tool). This study is limited with that respect because it did not differentiate between the two settings. In fact, students were given the choice to use the learning tool for marks.

Finally, conclusions drawn are based on the use of a specific learning tool which was developed in-house. Other learning tools can have different designs, be developed for different platforms (in this case it was web-based) and used under different settings. This therefore may not generalize across a wide set of learning tools.

\section{Implications for Educators/Managers}

This research was motivated by an interest in understanding the role that personal innovativeness, enjoyment and playfulness play in mediating perceived usefulness. Our study shows that enjoyment has a strong significant mediating influence on perceptions of the learning tool usefulness. Our findings suggest that learning tools should be designed to include interactivities that are enjoyable. In the context where the learning tool usage is motivated by the score obtained, playfulness and perceived personal innovativeness do not mediate the PU-ATT relationship. In other words, more individuals that are more playful on the web do not have better attitudes about the use of learning tools, nor do they perceive the learning tool to be more useful.

The findings demonstrate the value of the contribution of enjoyment as a mediator to perceived usefulness of learning tools. With the continuous development of richer and more appealing inter- 
faces, the most important of experiences that are intrinsically motivating is enjoyment. This construct might dominate as a predictor of usage intentions. Course designers and managers that desire to successfully implement new learning tools in a higher education or training context need to be aware of this relationship in order to create an environment supportive to the state of enjoyment.

Another key implication for designers/managers relates to guidelines for the design of learning tools. Enjoyment is more likely to be experienced with learning tools that are interactive and motivating. Paying close attention and to integrating interactive features in the design of learning tools and providing incentives to motivate its usage would assist those responsible for diffusion of the learning tools via the mediating effect of enjoyment.

\section{References}

Abbad, M.M., Morris, D., \& De Nahlik, C. (2009). Looking under the bonnet: Factors affecting student adoption of e-learning systems in Jordan. The International Review of Research in Open \& Distance Learning, 10(2). Retrieved 08 May. 2012 from http://www.irrodl.org/index.php/irrodl/article/view/596/1218

Agarwal, R., \& Karahanna, E. (2000). Time flies when you're having fun: Cognitive absorption and beliefs about information technology usage. MIS Quarterly, 24(4), 665-694.

Atkinson, M.A., \& Kydd, C. (1997). Individual characteristics associated with World Wide Web use: An empirical study of playfulness and motivation. Database for Advances in Information Systems, 28(2), 53-62.

Chang, K. M., \& Cheung, W. (2001). Determinants of the intention to use internet/www at work: A confirmatory study. Information \& Management, 39(1), 1-14.

Chau, K. Y. P. (1996). An empirical assessment of a modified technology acceptance model. Journal of Management Information Systems, 13(2), 185-204.

Davis, D. F. (1986). A technology acceptance model for empirically testing new end-user information systems:Ttheory and results (Doctoral Dissertation). Massachusetts Institute of Technology, Cambridge, MA.

Davis, D. F. (1989). Perceived usefulness, perceived ease of use, and user acceptance of information technology. MIS Quarterly, 13(3), 319-339.

Davis, D. F., Bagozzi, P. R., \& Warshaw, R. P. (1989). User acceptance of computer technology: A comparison of two theoretical models. Management Science, 35(8), 982-1003.

Davis, R., \& Wong, D. (2007). Conceptualizing and measuring the optimal experience of the eLearning environment. Decision Sciences Journal of Innovative Education, 5(1), 97-126. doi: 10.1111/j.15404609.2007.00129.x

Deci, L. E., \& Ryan, M. R. (1985). Intrinsic motivation and self-determination in human behavior. New York, NY: Plenum.

Hackbarth, G., Grover, V., \& Yi, M. Y. (2003). Computer playfulness and anxiety: Positive and negative mediators of the system experience effect on perceived ease of use. Information \& Management, 40(3), 221-232.

Lee, M.K.O., Cheung, C.M.K., \& Chen, Z. (2005). Integrating a motivational perspective into the Technology Acceptance Model. Information \& Management, 42(8), 1095-1104.

Liao, Z., \& Cheung, T. M. (2001). Internet-based e-shopping and consumer attitudes: An empirical study. Information \& Management, 38(5), 299-306.

Nov, O., \& Chen, Y. (2008). Personality and technology acceptance: Personal innovativeness in IT, openness and resistance to change. Hawaii International Conference on System Sciences, Proceedings of the 41st Annual, 448 - 448. doi:10.1109/HICSS.2008.348. 
Nunnally, J. C. (1978). Psychometric Theory (2nd ed.). New York, NY: McGraw-Hill.

Raman, A. (2011). University Management Information System (UMIS) acceptance among university student: Applying the Extended Technology Acceptance Model (ETAM). Journal of Studies in Education, 1(1). Retrieved 08 May. 2012 from http://www.macrothink.org/journal/index.php/jse/article/view/990

Rivard, S., \& Huff, S.L. (1988). Factors of success for end-user computing. Communications of the ACM, $31(5), 552-561$.

Saadé, R.G., \& Bahli, B. (2005). The impact of cognitive absorption on perceived usefulness and perceived ease of use in on-line learning: An extension of the technology acceptance model. Information \& Management, 42(2), 317-327.

Saadé, R. G., Nebebe, F., \& Tan, W. (2007).Viability of the technology acceptance model in multimedia learning environments: A comparative Study. Interdisciplinary Journal of Knowledge and Learning Objects, 3(1), 175-184.

Šumak, B., Heričko, M., \& Pušnik, M. (2011). A meta-analysis of e-learning technology acceptance: The role of user types, and e-learning technology types. Computers in Human Behavior, 27(6), 2067-2077.

Sun, H., \& Zhang, P. (2006). Causal relationships between perceived enjoyment and perceived ease of use: An alternative approach. Journal of the Association for Information Systems, 7(9), 618-645.

Sun, H., \& Zhang, P. (2008). An exploration of affect factors and their role in user technology acceptance: Mediation and causality, Journal of the American Society for Information Science \& Technology, 59(8), 1252-1263.

Terzis,V., Moridis, C. N., \& Economides, A. A. (2012). The effect of emotional feedback on behavioral intention to use computer based assessment. Computers \& Education, 59(2), 710-721.

Triandis, H. C. (1980). Values, attitudes, and interpersonal behavior. In H. E. Howe, Jr. \& M. M. Page (Eds.), Nebraska Symposium on Motivation, 1979: Beliefs, Attitudes, and Values (pp.195-259). Lincoln, NE: Univ. of Nebraska Press.

Venkatesh, V. (1999). Creation of favorable user perceptions: Exploring the role of intrinsic motivation. MIS Quarterly, 23(2), 239-260.

Venkatesh, V., \& Davis, D. F. (2000). A theoretical extension of the technology acceptance model: Four longitudinal field studies. Management Science, 46(2), 186-204.

Wang, Y. S., Lin, H. H., \& Liao, Y. W. (2012). Investigating the individual difference antecedents of perceived enjoyment in students' use of blogging. British Journal of Educational Technology, 43(1), 139152.

Yager, S. E., Kappleman, L. A., Maples, G. A., \& Prybutok, V. R. (1997). Microcomputer playfulness: Stable or dynamic trait. Data Base, 28(2), 43-51. 


\section{Appendix. Measures of Study Variables}

\begin{tabular}{|c|c|c|}
\hline Construct & Item & Measure \\
\hline \multirow[t]{3}{*}{$\begin{array}{l}\text { Perceived Usefulness } \\
\text { (PU) }\end{array}$} & PU1 & $\begin{array}{l}\text { Using the 'learning tool' would reduce my ability to perform well } \\
\text { in the course. }\end{array}$ \\
\hline & PU2 & $\begin{array}{l}\text { Using the 'learning tool' in the course enables me to accomplish } \\
\text { better grades. }\end{array}$ \\
\hline & PU3 & $\begin{array}{l}\text { Using the 'learning tool' would enhance my performance in the } \\
\text { course. }\end{array}$ \\
\hline \multirow[t]{2}{*}{ Attitudes (ATT) } & ATT1 & The advantages of the 'learning tool' outweigh the disadvantages. \\
\hline & ATT2 & $\begin{array}{l}\text { Learning tools are not helpful for understanding better the course } \\
\text { content. }\end{array}$ \\
\hline \multirow[t]{3}{*}{ Enjoyment (E) } & E1 & I have fun interacting with the 'learning tool'. \\
\hline & E2 & Using the 'learning tool' bores me. \\
\hline & E3 & I enjoy using the 'learning tool'. \\
\hline \multirow[t]{3}{*}{$\begin{array}{l}\text { Perceived Personal } \\
\text { Innovativeness (PPI) }\end{array}$} & PPI1 & $\begin{array}{l}\text { If I heard about a new information technology, I would look for } \\
\text { ways to experiment with it. }\end{array}$ \\
\hline & PPI2 & In general, I am hesitant to try out new information technologies. \\
\hline & PPI3 & I like to experiment with new information technologies. \\
\hline \multirow{4}{*}{$\begin{array}{l}\text { Playfulness on the } \\
\text { Web (PW) }\end{array}$} & PW1 & When using the web I am imaginative. \\
\hline & PW2 & When using the web I am playful. \\
\hline & PW3 & When using the web I am inventive. \\
\hline & PW4 & When using the web I am creative. \\
\hline \multirow[t]{2}{*}{ Intention to Use (I) } & I1 & $\begin{array}{l}\text { I intend to take more courses using online 'learning tool' in the } \\
\text { future. }\end{array}$ \\
\hline & I2 & his 'learning tool'. \\
\hline
\end{tabular}




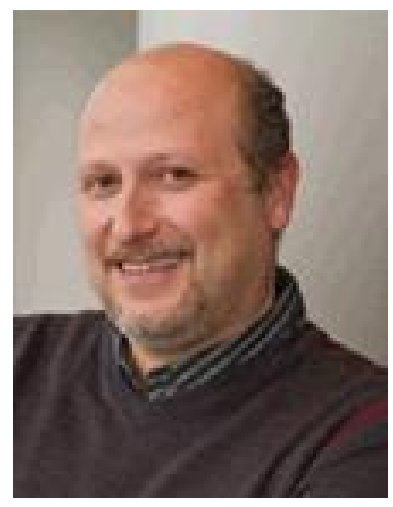

\section{Biographies}

Dr. Raafat George Saade has been teaching in the faculty since 1998. He obtained his Ph.D. in 1995 (Concordia University) after which he received the Canadian National Research Council postdoctoral fellowship, which he completed at McGill University in Montreal. Dr. Saade has published in journals such as Information \& Management, Decision Sciences, and Expert Systems with Applications. His research interests include the development and assessment of information systems, and the supply chain of digital information products.

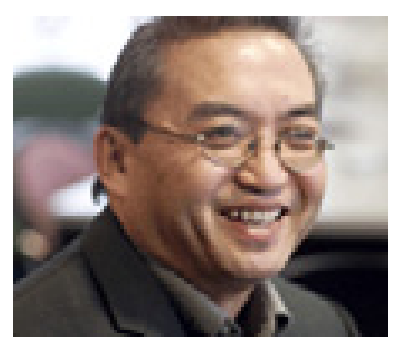

Dr. Dennis Kira is an associate professor at the Decision Sciences MIS department, John Molson School of Business, Concordia University, Canada. He has been with the Faculty since 1983. He obtained his Ph.D. from University of British Columbia. Dr. Kira teaches System design, decision support systems, data management, data mining, Internet related programming, and e-commerce His research activities include Ecommerce, web design, distance learning, decision making under uncertainty, neural networks, machine learning, and financial modeling. Dr. Kira has published in IEEE, ORQ and management science among other journals.

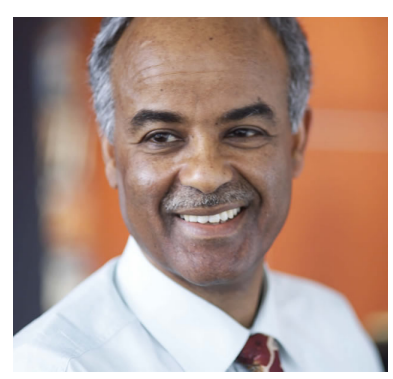

Fassil Nebebe (Ph.D., P.Stat.) is a Professor and Chair of the Department of Decision Sciences \& MIS of the John Molson School of Business, Concordia University, Montreal, Canada. His research focuses on statistical methods using Bayesian modeling and has made contributions with results published in different areas such as small area estimation, the bootstrap, Gibbs sampling, statistical computing, regression models and simulated MLE. He has served as Managing Editor of Liaison - The Newsletter of the Statistical Society of Canada (2004 - 2007), and as President of the Statistical Society of Montreal (2002/2003). He is the founding President of SSENA (1999-2002). 